\title{
RESPON SISWA PADA PEMBELAJARAN REALISTIK DENGAN MEDIA GEOGEBRA MATERI LINGKARAN SISWA KELAS VIIIA DI SMP NEGERI 2 SUGIO
}

\author{
Saptono \\ SMPN 2 Sugio, Lamongan, Jawa Timur \\ saptno@gmail.com
}

\begin{abstract}
ABSTRAK
Respon siswa pada Pembelajaran Realistik dengan Media GeoGebra materi lingkaran siswa kelas VIIIA di SMP Negeri 2 SugioPerkembangan ilmu pengetahuan teknologi dan informasi yang sangat cepat, berdampak pada kurangnya aktifitas belajar dan menurunnya motivasi belajar siswa di sekolah. Siswa lebih menyukai acara sinetron di Televisi atau lebih suka bermain dengan handphone dari pada memperhatikan pembelajaran oleh guru di sekolah. Suka atau tidak suka kita sebagai guru harus kreatif dan inovatif terhadap berbagai strategi/metode atau model pembelajaran, sehingga ada pemecahan masalah pada kurangnya peningkatan aktifitas belajar serta kurangnya peningkatan motivasi belajar.

Salah satu tindakan yang penulis lakukan adalah malalui pembelajaran Realistik dengan media GeoGebra. Pembelajaran Realistik menitik beratkan pada pengalaman nyata untuk mendapatkan atau membuktikan konsep matematika.Sedangkan Media GeoGebra merupakan program media pembelajaran yang multi fungsi dan banyak menu serta diharapkan mendapat respon yang baik serta dapat menambah motivasi belajar siswa khususnya siswa kelas VIII di SMP Negeri 2 Sugio tahun 2014/2015.
\end{abstract}

Kata kunci : pembelajaran Realistik, Media GeoGebra, Aktivitas,motivasi belajar.

\begin{abstract}
ABSTRAK
Students response to RealisticLearning with Media GeoGebra material circle VIIIA students in Junior High School 2 Sugio. The development of science and technology information very quickly, have an impact on the lack of learning activities and decrease students' motivation in school. Students are more like a sinetron on television shows or prefer to play with mobile phones of the notice by the teacher learning at school. Like it or not we as teachers must be creative and innovative strategies / methods or models of learning, so there is a problem solving on improving the learning activities as well as on increasing the motivation to learn.

One of the actions that the author did was through learning Realistic with GeoGebra media. Realistic learning focuses on real experience to gain or prove mathematical concepts. While Media GeoGebra is a program that is multi-functional learning media and a lot of menus and is expected to get a good response and can increase students' motivation, especially in the eighth grade students of SMP Negeri 2 Sugio year 2014/2015.
\end{abstract}

Keywords: Realistic learning, Media, GeoGebra, activities, motivation to learn.

\section{Pendahuluan}

Perkembangan ilmu pengetahuan

teknologi dan informasi berpengaruh

pada perubahan sikap seseorang, termasuk pada siswa setingkat SMP. Televisi dan handphone bukan barang mewah, lebih dari $70 \%$ anak SMP sudah memiliki handphone. Anak-anak lebih 
meyukai acara di televisi dan menggunakan handphone daripada mengikuti pembelajaran di sekolah. Akibatnya aktivitas belajar dan motivasi belajar di sekolah menurun. Dalam UU nomor 20 tahun 2003 pasal 40 (2) disebutkan bahwa pendidik dan tenaga kependidikan berkewajiban menciptakan suasana pendidikan yang bermakna, menyenangkan, kreatif, dinamis, dan dialogis. Untuk mengatasi permasalahan ini, penulis melakukan penelitian tindakan kelas (PTK) melalui pembelajaran Realistik dengan media GeoGebra agar pembelajaran lebih bermakna, menyenangkan, meningkatkan aktivitas dan motivasi dalam pembelajaran matematik

Menurut Sumaryanta, 2014, Yang dijadikan dasar untuk pengembangan Pembelajaran Realistik pada pelajaran matematika yakni dasar pemikiran Hans Freudenthal, dimana ia mempunyai pandangan bahwa matematika merupakan aktifitas manusia (human activities) dan harus dikaitkan dengan dunia nyata/realita sehingga peserta didik harus diberi kesempatan menemukan kembali (to reinvent) matematika melalui bimbingan guru dan bahwa penemuaan kembali (reinvention) ide atau konsep tersebut harus dimulai dari penjelajahan dari berbagai situasi dan persoalan "dunia riil" Pembelajaran realistik dalam matematika didasarkan pada tiga prinsip utama, yaitu : (1). Menemukan kembali dengan bimbingan dan matematisasi progresif (guided reinvention anda progressive mathematizing), fenomena yang bersifat didaktik (didactical phenomenology), dan (3) mengembangkan model sendiri (self developed models)(Gravemeijer, 1994; dalam Sumaryanta, 2014; 01-12)

Guidedreinvention

anda progressive mathematizing berarti siswa diberi kesempatan mengalami proses bagaimana konsep matematika ditemukan. Pembelajaran dimulai dengan masalah kontekstual/realistik selanjutnya diharapkan siswa dapat menemukan kembali konsep matematikanya. Didactical phenomenology berarti situasi yang diberikan mempertimbangkan kemungkinan aplikasi dalam pembelajaran dan sebagai titik tolak pematematikaannya. Self developed models berarti model dibuat sendiri oleh siswa selama pemecahan masalah. Model awalnya dari situasi yang dikenal siswa, kemudian dengan generalisasi dan formalisasi menjadi model sesuai penalaran matematika

Implementasi pembelajaran matematika realistik dalam pembelajaran di kelas tidak dapat dilepaskan dari berbagai karakteristik dan prinsip-prinsip yang mendasari model pembelajaran 
ini.Oleh karena itu, sebelum mengimplementasikan pembelajaran matematika realistik, guru harus memahami dengan sungguh-sungguh berbagai karakteristik dan prinsip-prinsip tersebut.

Secara umum implementasi pembelajaran matematika realistik di kelas dilakukan dengan:

a. Memulai pembelajaran dengan masalah kontekstual yang diambil dari dunia nyata. Masalah yang digunakan sebagai titik awal pembelajaran harus nyata bagi siswa agar mereka dapat langsung terlibat dalam situasi yang sesuai dengan pengalaman mereka.

b. Menjembatani dunia abstak dan nyata dengan model. Model harus sesuai dengan tingkat abstraksi yang harus dipelajari siswa. Di sini model dapat berupa keadaan atau situasi nyata kehidupan siswa, seperti cerita-cerita lokal atau bangunanbangunan yang ada di tempat tinggal siswa. Model dapat pula berupa alat peraga yang dibuat dari sekitar siswa.

c. Memberi keleluasaan siswa menggunakan strategi, bahasa, atau simbol mereka sendiri dalam proses mematematikakan dunia mereka. Artinya, siswa memiliki kebebasan mengekspresikan hasil kerja dalam menyelesaikan masalah nyata yang diberikan guru.

d. Membangun proses pembelajaran yang interaktif. Interaksi baik antara guru dan siswa maupun antara siswa dengan siswa merupakan elemen yang penting dalam pembelajaran matematika. Di sini siswa dapat berdiskusi dan bekerjasama dengan siswa lain, bertanya dan menanggapi pertanyaan, serta mengevaluasi pekerjaan.

e. Menghubungkan bagian-bagian dalam matematika, dengan disiplin ilmu lain, dan dengan masalah dari dunia nyata diperlukan sebagai satu kesatuan yang saling kait mengait dalam penyelesaian masalah.

Kegiatan pembelajaran Realistik untuk menentukan pendekatan Nilai Phy $(\pi)$ di SMP Negeri 2 Sugio dilakukan dengan langkah-langkah sebagai berikut : a. Melakukan pengukuran Keliling dan diameter benda berbentuk lingkaran seperti gambar di bawah ini : 

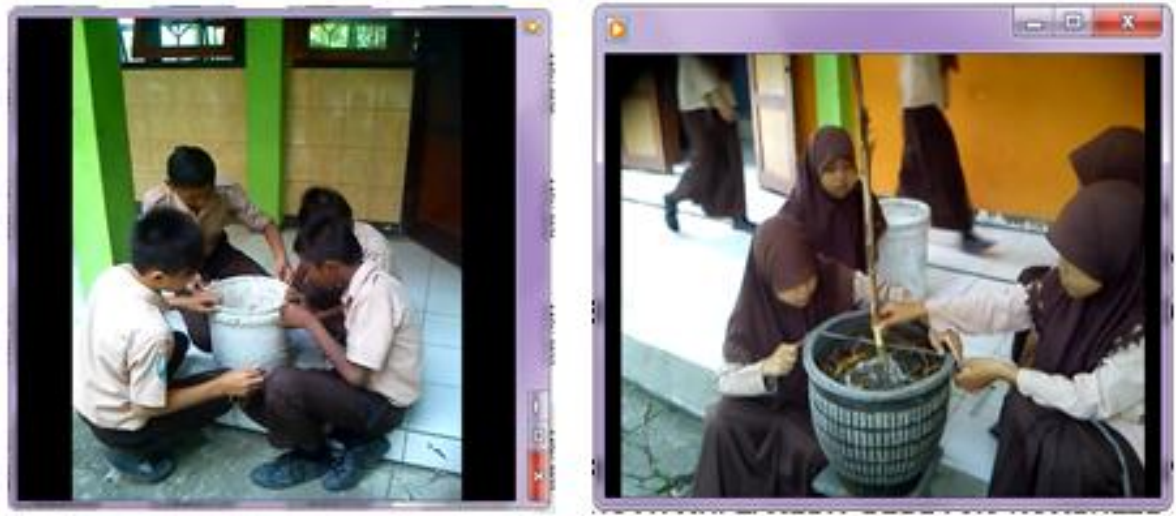

Gambar 1. Mengukur Keliling dan diameter benda berbentuk lingkaran

b. Mencatat hasil pengukuran ke dalam tabel di bawah ini :

Tabel 1. Tabel hasil pengukuran Keliling dan diameter lingkaran

\begin{tabular}{|c|c|c|c|c|}
\hline No & Nama benda & Keliling(K) & Diameter(d) & K/d \\
\hline 1 & ..................... & 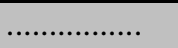 & ................ & \\
\hline 2 & $\ldots .$. & ........... & .................. & ............ \\
\hline 3 & 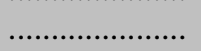 & …............... & ................... & ............ \\
\hline 4 & ....................... & .................. & ................. & ............ \\
\hline & Rata-rata & ................... & .................. & ............ \\
\hline
\end{tabular}

c. Lakukan diskusi informasi kelas untuk mendapatkan pendekatan nilai $\operatorname{Phy}(\pi)$, guru membimbing untuk mengarahkan bahwa nilai $\pi=$ 3,142857 yang pada akhirnya ditulis dalam 2 angka desimal menjadi $\pi=$ 3,14

d. Kembangkan persamaan perbandingan $\mathrm{K} / \mathrm{d}=\pi$ ke dalam bentuk $\mathrm{K}=\pi \mathrm{d}$,

Karena $\mathrm{d}=2 \mathrm{r}$, maka vormula Keliling lingkarannya menjadi $\mathrm{K}=$ $2 \pi \mathrm{r}$

Dengan $\mathrm{K}=$ Keliling lingkaran, $\mathrm{d}=$ diameter, $r=$ jari-jari, dan $\pi=3,14$ e. Berikan soal latihan untuk menerapkan vormula Keliling lingkaran dan pengembangannya

Salah satu program komputer yang dapat dimanfaatkan sebagai media pembelajaran matematika dalah program GeoGebra. GeoGebra dikembangkan oleh Markus Hohenwarter pada tahun 2001. Menurut Hohenwarter (2008), GeoGebra adalah program komputer untuk membelajarkan matematika khususnya geometri dan aljabar. Program ini dapat dimanfaatkan secara bebas yang dapat diunduh dari w.geogebra.com. Adapun contoh tampilan program Geogebra dalam pembelajaran di kelas dapat dilihat seperti gambar di bawah ini : 

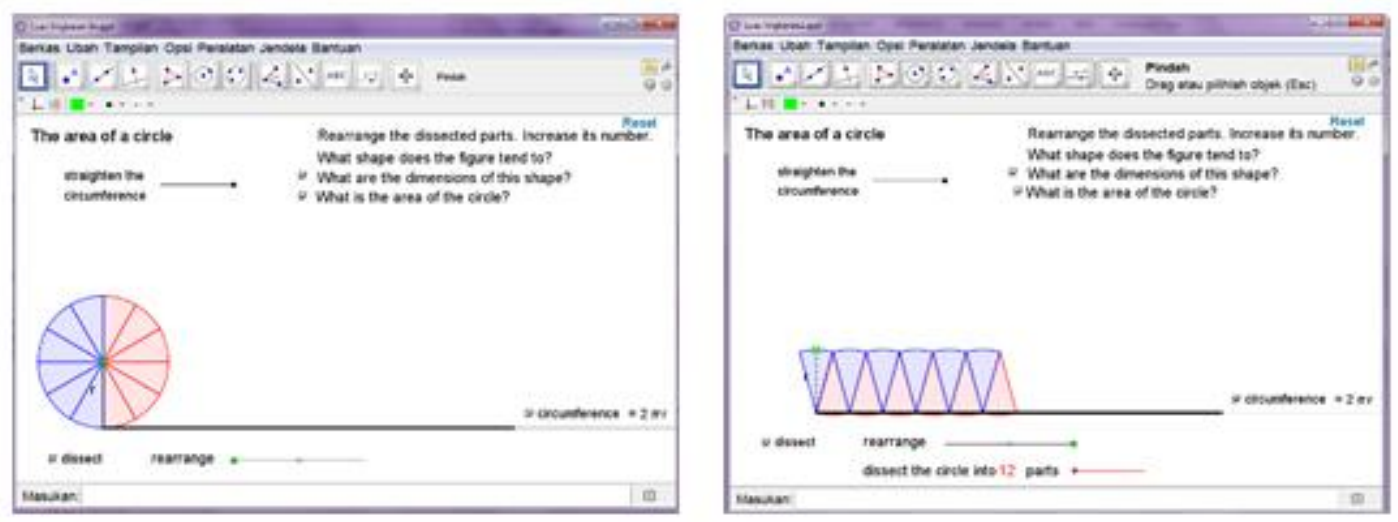

Gambar 2. Tampilan Media Geogebra materi Luas Lingkaran

\section{Metodologi Penelitian}

KegiatanPembelajaranRealistikde ngan media

Geogebramaterilingkaransiswakelas

VIIIA SMP Negeri 2Sugiodenganalamat

di JalanGondanglornomor

154

SugioKabupatenLamonganPropinsiJawa

Timur.

Banyaknyarombonganbelajarpada

Kelas VIII ada 7 kelasdenganjumlahsiswa 194.

MengingatPenulispadatahunpelajaran 2014/2015 semester genap mengajardikelas VIIIA, maka sebagaisubyekanalisispembelajaran realistik inidipilihsiswakelas VIIIA denganjumlah 28 anak, rinciannya siswa laki-lakinya 11 dan siswa perempuan banyaknya 17

Kegiatan dilakukan selama 4 bulan pada semester Genap tahun pelajaran 2014/2015.Kegiatan penelitian diawali pada minggu ke-3 bulan Januari 2015 sampai dengan minggu ke-3 bulan
Mei 2015. Sebagai gambaran untuk memperoleh informasi tentang penerapanpembelajaran Realistik dengan media GeoGebra terhadap kelas VIIIA sebagai subyek kegiatan dilaksanakan sesuai pada jam mengajar dengan materi Lingkaran

Prosedur kerja dari pembelajaran Realistik dengan media Geogebra yang dikemas melalui Deskripsi Analisis inovasi pembelajaran dengan bentuk siklus Kemmis dan Tagart, Pembelajaran dengan multi metode dan media GeoGebra.Secara administrasi tindakan guru dapat berpedoman pada Skenario pembelajaran yang dibuat oleh guru.

Secara garis besar, siklus I dapat diinformasikan sebagai berikut:(1). Guru melaksanakan tindakan proses belajar mengajar sesuai dengan Standar Kompetensi dan Kompetensi Dasar yang diajarkan pada saat itu dan sesuai dengan jadwal mengajar dengan LKS untuk melakukan kegiatan mengukur Keliling 
benda yang berbentuk lingkaran dan mengukur diameternya; (2). Setelah itu diadakan diskusi informasi untuk menentukan pendekatan nilai Phy $(\pi)$ sehingga bisa dibuktikan melalui pengalaman nyata bahwa nilai Phy $(\pi)$ mendekati 3,14.

Adapun pada siklus II dapat dilakukan seperti berikut : (1) Pada pertemuan berikutnya dibahas Luas lingkaran dengan media Geogebra. Selama proses pembelajaran guru bertugas mengendalikan dan mengamati siswa agar proses pembelajaran selalu dalam kondisi yang menyenangkan dan terarah pada tujuan sehingga pembelajaran lebih bermakna; (2)Sebagai refleksi hasil pembelajaran, berikan beberapa soal latihan dan berikan angket model Arc sebagai respon hasil pembelajaran untuk mengukur motivasi siswa

Sedangkan siklus III dapat dilakukan sebagai berikut:(1) Membahas Luas lingkaran dengan GeoGebra dan siswa membuktikan menentukan luas lingkaran dengan menggambar pada lembaran dan menggunting serta menempel pada lembaran kertas; (2) Sebagai refleksi hasil pembelajaran, berikan soal latihan dan berikan angket model Arc sebagai respon hasil pembelajaran untuk mengukur motivasi siswa pada pembelajaran matematika.

Teknik dan Instrumen Pengumpulan Data : (1) Tabel Aktivitas siswa; (2) Instrumen Data menggunakan Angket model Arc; (3) Soal Ulangan Harian; (4) Angket Kesan dan Pesan.

Analisa data dilakukan dengan mendeskripsikan hasil angket dan hasil nilai ulangan harian dalam bentuk data kuantitas, Hasil Pengisian Kesan dan Pesan, serta Hasil monitoring Aktivitas belajar siswa

$$
\text { IndikatorKeberhasilan : }
$$

Adanya respon positip dari siswa terhadap Pembelajaran Realistik yang menunjukkan dapat meningkatkan aktifitas belajar siswa kelas VIIIA materi lingkaran di SMP Negeri 2 Sugio; (2) Adanya respon positip dan kesan menyenangkan pada Media Geogebra yang dapat menunjukan adanya peningkatan motivasi belajar siswa kelas VIIIA SMP Negeri 2 Sugio.

\section{Hasil dan Pembahasan Penelitian}

Aktivitas belajar pada pengerjaan LKS Siklus I, II, dan III dapat dilihat pada tabel berikut ini:

Tabel 2. Rekap hasil Monitoring aktivitas belajar

\begin{tabular}{lllllllll}
\hline No & Indikator & \multicolumn{9}{c}{ Jumlah siswa dan prosentase Siklus I, II, III } & Rerata \\
\cline { 3 - 8 } & & I & $\%$ & II & $\%$ & III & $(\%)$ & $\%$ \\
\hline
\end{tabular}




\begin{tabular}{llccccccc}
\hline $\mathbf{1}$ & Tidak suka membuang waktu & 24 & 85,71 & 28 & 100,00 & 27 & 96,43 & 94,05 \\
$\mathbf{2}$ & Kesibukan yang sangat tinggi & 24 & 85,71 & 26 & 92,86 & 26 & 92,86 & 90,48 \\
$\mathbf{3}$ & Mengerjakan tepat waktu & 27 & 96,43 & 25 & 89,29 & 28 & 100,00 & 95,24 \\
$\mathbf{4}$ & Mengerjakan sebaik mungkin & 23 & 82,14 & 27 & 96,43 & 27 & 96,43 & 91,67 \\
$\mathbf{5}$ & Bergairah belajar & 25 & 89,29 & 28 & 100,00 & 28 & 100,00 & 96,43 \\
$\quad$ Rata-rata & & 87,86 & & 95,71 & & 97,14 & 93,57 \\
\hline
\end{tabular}

Dari ketiga Siklus diperoleh Ratarata 93,57 ; sedangkan Kriteria Ketuntasan Minimal pembelajaran Matematika di SMP Negeri 2 Sugio 75,00 maka dapat diartikan Pembelajaran tuntas. Semua indikator terpenuhi dengan baik dalam arti rata-rata skor diatas 90 . Artinya aktivitas siswa dengan pembelajaran Realistik tergolong sangat baik

Motivasi dalam pembelajaran matematika dapat dilihat dari tabel 2 nomor 5 Indikator Bergairah belajar memperoleh skor 96,43 artinya melalui pembelajaran Realistik dengan media
GeoGebra respon siswa sangat tinggi. Termasuk ketika siswa diminta mengisi angket Kesan dan pesan, semua anak mengatakan senang dengan pembelajaran matematika. Kondisi ini sebenarnya juga dipengaruhi oleh gaya mengajar gurunya, dalam hal ini anak merasa guru mengajarnya menyenangkan dan terkesan lucu sehingga dapat penulis katakan bahwa lebih dari $90 \%$ respon siswa positip, siswa merasa senang, dan semangat dalam belajar.Sebagai sampel hasil pengisian angket Kesan dan pesan dapat dilihat seperti gambar di bawah ini

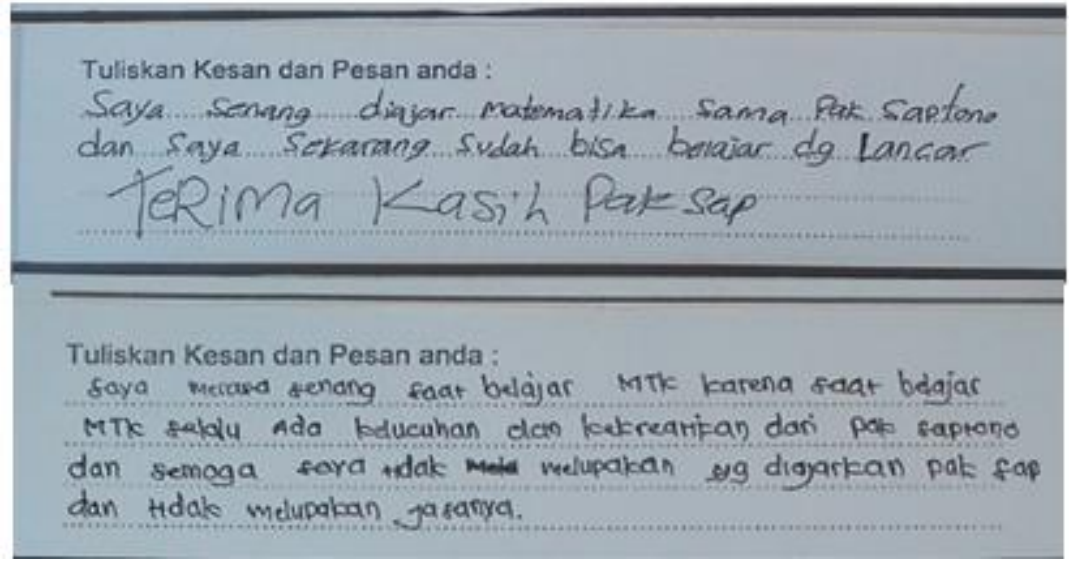

Gambar3. Pengisian angket Kesan dan Pesan pada pembelajaran matematika

\section{Kesimpulan}

Berdasarkan hasil analisis data, kesimpulan dalan penelitian ini adalah dengan pembelajaran Realistik dan Media GeoGebra respon siswa positip, dalam arti : (1) aktivitas belajar siswa sangat 
tinggi; (2) bergairah dalam belajar; (3) dapat meningkatkan motivasi belajar matematika; (4) mengerjakan tepat waktu; (5) tidak suka membuang waktu; (6) belajar menyenangkan dan lucu.

\section{Pustaka}

Mendikbud. 2014. Peraturan Menteri Pendidikan dan Kebudayaan Republik Indonesia nomor 61 tahun 2014 tentang Kurikulum Tingkat Satuan Pendidikan pada Pendidikan dasar dan Pendidikan menengah.

Mendikbud. 2014. Peraturan Menteri Pendidikan dan Kebudayaan Nomor 103 tahun 2014 tentang pembelajaran pada pendidikan dasar dan pendidikan menengah
Sumaryanta,2014,

Pembelajaran matematika Realistik dan strategi implementasinya di kelas,

Mahmudi, Ali. (2011). Pemanfaatan GeoGebra dalam pembelajaran Matematika.

http://www.publications.uni.lu/record/27 18/files/ICME11-TSG16.pdf

Hohenwarter, M, et al. (2008). Teaching ang learning Calculus with Free Dynamic Mathematic Software GeoGebra.http://GeoGebra.org/pu blication.uni.lu/record /2718/files/ICME11-TGS16.pdf.

Riyanto, Yatim, (2010), Paradigma baru Pembelajaran, Jakarta : Kencana Prenada Media Group.

Dudeja, Ved, (2014). Jelajah Matematika 2 SMP Kelas VIII, Surakarta : Yudhistira 